\title{
Necrológica
}

\section{Robert K. Merton}

\section{José Antonio Noguera}

Universitat Autònoma de Barcelona. Departament de Sociologia

jose.noguera@uab.es

Robert King Merton, uno de los sociológos más renombrados del siglo XX, falleció en Manhattan el pasado 23 de febrero de 2003 a la edad de 92 años, víctima de una larga enfermedad. La importancia de sus contribuciones para el desarrollo de la sociología moderna fue tal que se debe admitir que no exageraba J. R. Cole, el rector de la Universidad de Columbia, donde Merton pasó la mayor parte de su carrera, cuando dijo que si hubiera un premio Nobel para los sociológos, Merton lo hubiese conseguido sin lugar a dudas (siendo así que su hijo, Robert C. Merton, sí ganó el Nobel de Economía en 1997).

Merton nació en Filadelfia en el seno de una humilde familia judía proveniente de Europa del Este; su nombre original era Meyer R. Schkolnick, pero, a la edad de 14 años, lo americanizó, convirtiéndose en Robert K. Merton — siendo "Merton» una derivación de "Merlin», sobrenombre que usaba entre amigos y familiares debido a su afición por los trucos de magia- Pese a una adolescencia problemática, en la que se integró en bandas juveniles urbanas, Merton se acabó licenciando por la Universidad de Temple. Su propia vida fue, en cierto sentido, un ejemplo de la lucha contra las causas de la anomia y la desviación, así como de las consecuencias imprevistas de la acción, la serenditipy (descubrimiento casual e inesperado), y otros procesos que se dedicó a estudiar durante su carrera.

Durtante sus estudios de doctorado en Harvard, Merton se formó de la mano de T. Parsons —el otro gran sociólogo estructural-funcionalista-, de P. A. Sorokin — con quien, a diferencia de Parsons, siempre conservó una buena relación-, y del bioquímico L. J. Henderson — quien inspiró algunas de las metáforas organicistas del funcionalismo sociológico-; sus lecturas de Durkheim y Simmel ejercieron también una influencia duradera en su obra; pero su principal mentor fue, según confesión propia, el historiador de la ciencia G. Sarton, responsable de que la tesis doctoral de Merton, leída en 1936 y publicada dos años más tarde, tratase sobre las relaciones entre ciencia, tecnología y sociedad en la Inglaterra del siglo XVII; con ella abriría Merton un nuevo campo de investigación al cual habría de dedicar notables esfuerzos durante toda su carrera: el de la sociología de la ciencia.

Tras un breve paso por la Universidad de Tulane (Nueva Orleans), en 1940 Merton llega a la Universidad de Columbia (Nueva York); allí conoce a Paul Lazarsfeld, sociólogo de origen austríaco con quien colaborará durante décadas 
en la Oficina de Investigación Social Aplicada, que Merton dirigió hasta 1980. Allí también fructificaron gran parte de los trabajos que componen su libro Teoría y estructura social, publicado por primera vez en 1949, revisado en múltiples ocasiones, y que se convertiría en un clásico de la teoría sociológica y en uno de los libros más leídos de la sociología del siglo XX. Merton fue elegido presidente de la Asociación Americana de Sociología en 1957, y, en 1994, el presidente Clinton le concedió la Medalla Nacional de la Ciencia, máximo galardón científico norteamericano, que se entregaba por vez primera a un sociólogo. La institucionalización de la sociología como disciplina académica y científica en los Estados Unidos sería inimaginable sin la figura de Merton, hasta el punto de que a veces se le conocía como "Mr. Sociology».

La obra de Merton constituye un diáfano ejemplo de un talante intelectual típicamente norteamericano, basado en un lenguaje directo y claro, libre de jerga y de oscuridades innecesarias, orientado hacia la aplicabilidad empíri$\mathrm{ca}$, y en el cual los diversos trabajos no siguen un plan único diseñado "para toda una vida», sino que se van abordando a medida que surgen de forma espontánea diferentes intereses y líneas de investigación. No fue Merton un científico de los que producen "una gran idea», sino más bien muchas de tamaño más modesto, pero quizá por ello más operativas en el día a día de la investigación. En este sentido, resulta extraordinaria la gran diversidad de temas y campos de estudio que Merton cultivó a lo largo de su carrera, sin que ello le llevase nunca a plantearse, como Parsons, la elaboración de una "gran teoría» omniabarcante para la ciencia social; al contrario, se fue centrando en la cuidadosa construcción de objetos específicos de estudio (algo que, probablemente, tiene que ver con la relativa vigencia y utilidad empírica de buena parte de su obra comparada con la de Parsons). Aún así, cabe destacar algunas líneas claras de continuidad en la obra de Merton: desde las trazadas en sus estudios sobre la ciencia, hasta su preocupación por la integración del conflicto y la desviación social, o por las consecuencias imprevistas de la acción social.

A pesar de su compromiso explícito con el análisis funcional, la habitual clasificación de Merton como sociólogo «funcionalista» siempre ha resultado mucho más problemática que la de autores como Kingsley Davis o el propio Parsons. De hecho, debemos a Merton la primera gran crítica interna del funcionalismo (al cuestionar los postulados de unidad funcional, funcionalismo universal e indispensabilidad funcional), a pesar de que la llevase a cabo en el contexto de un intento por elaborar un paradigma científico de análisis funcional. Claramente, su eclecticismo y su espíritu crítico nunca fueron tan lejos como para cuestionar la validez de las explicaciones teleológicas típicas del funcionalismo (como parece evidente en su concepto de "funciones latentes», una de sus aportaciones más conocidas). Todavía en los años 80, Merton declaraba que pretendía re-elaborar los fundamentos de una perspectiva funcional para la sociología. Sin embargo, es también cierto que es el único, de entre los sociólogos funcionalistas, cuyos textos suelen leer hoy día con provecho -y aún con cierto placer-sociólogos de cualesquiera orientaciones teóricas. 
Hay en la obra de Merton hitos fundamentales para el desarrollo de la sociología del pasado siglo: su mencionada distinción entre funciones manifiestas y latentes fue muy utilizada por los cinetíficos sociales, tanto funcionalistas como de otras tradiciones teóricas. Estudió numerosos casos de consecuencias no queridas de la acción social, entre ellos, en uno de sus ensayos más afortunados, el de la profecía que se cumple a sí misma (self-fulfilling prophecy), así como el caso inverso de la profecía autodestructiva (defeating prophecy). Formuló la idea de las teorías de alcance intermedio (middle-range theories), como instrumento metodológico para escapar tanto a las especulaciones incontrastables de la "gran teoría» como al empirismo chato de la investigación social ateórica. Y, de hecho, el propio Merton elaboró por sí mismo numerosas teorías de ese tipo: por ejemplo, la teoría de la desviación social, que incluía una tipología de conductas desviadas o anómicas que todavía hoy se sigue utilizando en psicología social; o su teoría del grupo de referencia y la privación relativa, un caso donde los haya de auténtica serendipity, de descubrimiento casual a raíz de los resultados de una investigación —-El soldado americano- que no se dirigía a lograr tal hallazgo; o, en fin, su revisión de la teoría weberiana de la burocracia, o sus investigaciones también pioneras sobre los modernos medios de comunicación de masas y su efecto sobre el público. Todas estas preocupaciones las combinó Merton con la atención al desarrollo de nuevas técnicas de investigación, como la entrevista focalizada de grupo (focus group), que hoy se utiliza de forma masiva — y a veces, según Merton, abusivamente- en el márketing político y comercial, lo que le hizo exclamar: «I Wish I'd get a royalty on it» («ojalá la hubiera patentado»).

Pero donde el talento de Merton brilló con más intensidad fue probablemente en sus trabajos sobre sociología de la ciencia. Su fervor de auténtico pionero, al internarse en un campo de estudio sociológico casi por completo virgen, consiguió poner al descubierto los condicionantes institucionales y las relaciones sociales que estructuran la labor de la comunicad científica. Merton teorizó fenómenos como el efecto Mateo, esa injusta regla no escrita de dicha comunidad por la cual el prestigio llama automáticamente a más prestigio, y así sucesivamente. Estudió el ethos que subyace a la ciencia moderna y la convierte en un logro histórico tan peculiar, tan frágil, y tan a contracorriente, a veces, del resto de la estructura social y las pautas normativas dominantes (por sus imperativos de comunismo, desinterés, universalismo y escepticismo organizado). Rastreó los orígenes de dicho ethos hasta los valores del puritanismo protestante en el siglo XVII, ampliando una de las sugerencias que Weber hacía al final de La ética protestante y el espíritu del capitalismo. Y escribió un grandioso libro - A hombros de gigantes (1965) — sobre la originalidad, la creación, el plagio, la tradición y el progreso en el mundo científico e intelectual, cuya profundidad nada tiene que envidiar a otros más recientes abordajes sociológicos de temas similares mucho más pretenciosos y ampulosos que el suyo. La absoluta injusticia de que hoy día se suela designar la sociología de la ciencia de Merton, con cierto menosprecio, con el nombre de «programa débil», no hace más que confirmar la impresión, cada vez más extendida, de que sus aporta- 
ciones resultan hoy mucho más coherentes e informativas para el lector paciente y ecuánime que las estridencias y provocaciones supuestamente "epatantes» del autodenominado "programa fuerte» y todas sus secuelas irracionalistas. Muy al contrario, Merton quedará como el iniciador de una sociología de la ciencia rigurosa y con pretensión científica, a años luz del resentimiento autodestructivo de aquellos cuyo auténtico objetivo, de momento vano, es derribar epistemológica y socialmente una ciencia cuyas virtudes epistémicas muchas veces ni alcanzan a comprender, aunque sí, en el fondo y a su pesar, a envidiar.

Aunque Merton fue sin duda un sociólogo del mainstream, y no un outsider como Mills o Goffman, ello no implicaba las connotaciones de conservadurismo que muchas veces se ha asociado a su figura (o a la de Parsons). De hecho, sus posturas políticas eran claramente liberales (en el sentido progresista que el término tiene en los Estados Unidos), y abiertamente favorables a las campañas por los derechos civiles y la integración de las minorías que se desarrollaron durante los años 50 y 60 del pasado siglo. Los estudios de Merton sobre integración y desviación social, por ejemplo, fueron devisivos en el proceso judicial por el cual el Tribunal Supremo de los Estados Unidos abolió la segregación racial en las escuelas públicas.

A Merton, de quien alguien dijo que estaba «sorprendentemente bien informado de todo, desde el baloncesto hasta Kant», le recordaremos como una de las figuras más representativas de la tarea del sociólogo. Su muerte cierra la página de la sociología del siglo XX. Amado y temido por igual por sus estudiantes — asustados muchas veces de su crítica amable pero implacable-, se contaban entre sus virtudes intelectuales la paciencia - habitual en alguien aficionado a fumar en pipa y a los gatos (tenía 15), y que le permitió superar seis cánceres diferentes_- la constancia —empezaba a trabajar a las 4:30—, la autoexigencia - revisó en innumerables ocasiones sus propios escritos-, pero, sobre todo, su pasión por convertir el detalle inadvertido, la anécdota y la erudición en algo científicamente útil y teóricamente significativo incluso para el gran público.

\section{Principales libros traducidos al español}

Ciencia, tecnología y sociedad en la Inglaterra del siglo XVII (1938). Madrid: Alianza, 1984.

Teoría y estructura sociales $(1949,1957,1968)$. México: Fondo de Cultura Económica, 1980.

A hombros de gigantes (1965. Barcelona: Península, 1990.

La sociología de la ciencia (1973). Madrid: Alianza, 1985 (2 vols.).

Ambivalencia sociológica y otros ensayos (1970). Madrid: Espasa-Calpe, 1980. 